\title{
Teaching with heart and soul
}

\author{
Sarah Mercer, University of Graz, Austria \\ sas_mercer@yahoo.com
}

\author{
Christina Gkonou, University of Essex, UK*1 \\ cgkono@essex.ac.uk
}

\begin{abstract}
In this chapter, we argue that emotional (EI) and social intelligence (SI) are core competencies for language teachers. EI and SI refer to an individual's abilities in understanding and managing their own emotions as well as their interpersonal relationships. Both competencies are especially important for language teachers given the inherently interpersonal and communicative nature of contemporary foreign language learning and teaching. Nevertheless, they are rarely addressed in teacher training programmes and are notably absent from the research landscape with respect to SLA. We report on the results of a survey on the EI and SI of 890 EFL teachers from across the globe. The survey consisted of items which measured both trait and educational-context-specific EI and SI. The results revealed a strong positive correlation between trait EI and SI and educational-context-specific EI and SI. Female teachers were found to score slightly higher on both constructs than male teachers. In addition, a significant positive correlation was found between levels of EI and SI and teaching experience. Multiple regression analyses also showed that gender and teaching experience made the greatest contribution to teachers' trait EI and SI. We conclude our chapter by reflecting on the practical implications suggesting that EI and SI are skills that should be incorporated into pre-service and in-service teacher training courses.
\end{abstract}

\section{Introduction}

This chapter is based on our deep conviction in the importance of emotional (EI) and social intelligence (SI) in the language classroom. We begin by outlining what is meant by these two terms and we present our rationale for why we believe in their centrality in education generally, but especially in the field of language learning in which interpersonal skills play such a key role. Importantly, we also argue that although EI and SI might be seen as innate traits, our preference is to approach them as skills which can be developed such as in training programmes in order to support effective teaching.

We report on a study designed to examine the levels of EI and SI amongst English as a foreign language (EFL) teachers across the globe, to investigate possible patterns across selected demographic variables and, most importantly, to establish whether there may be justification

\footnotetext{
${ }^{1}$ This document is an output from the ELT Research Award scheme funded by the British Council to promote innovation in English language teaching research. The views expressed are not necessarily those of the British Council.
} 
in arguing for a domain-specific conceptualisation of EI and SI. We conclude the chapter by reflecting on the specific implications of this study and our consideration of the literature for language teacher education programmes at both the pre-service and in-service levels.

\section{Literature review}

\subsection{Understanding emotional and social intelligence}

The concept of EI can be traced back to the theory of multiple intelligences proposed by Howard Gardner (1983), which included a type of intelligence that he referred to as 'the personal intelligences'. This comprised an intrapersonal element, which involves looking inward towards one's self, and an interpersonal element, which is more outward looking towards other individuals. He argues that these are two distinct types of intelligences but interdependent and partially overlapping (ibid: 255). It is interesting to note that Gardner's original conceptualisation did not particularly highlight the role of the emotions (Hatch and Kornhaber 2006), rather that dimension emerged more strongly from later conceptualisations. Following from Gardner, various researchers have taken up the terms and concepts. Perhaps one of the most noted were Salovey and Mayer (1990) who researched the factors underlying effectively functioning societies and were the first to use the term 'emotional intelligence'. However, it was Goleman (1995) who made the term common currency through his popular science book of the same name. In his understanding of the term, there are five key domains of EI: self-awareness, self-regulation, motivation, empathy, and social skills. He defines EI specifically as, "the capacity for recognising our own feelings and those of others, for motivating ourselves, and for managing emotions well in ourselves and in our relationships" (Goleman 1998: 317).

Although as proposed in Gardner's original conceptualisation, there is much overlap between EI and SI, we share his view that they focus on two different perspectives with one more selforiented and one more other-oriented. Goleman (2006) explains the distinction in terms of a focus on one-person psychology within an individual (EI) compared to the two-person psychology that emerges from people interacting (SI). Goleman's own work on SI builds on previous scholars such as Gardner and perhaps most notably, Thorndike (1920), who was one of the first to name 'social intelligence', which he defined as "the ability to understand and manage men and women, boys and girls - to act wisely in human relations" (ibid: 228). In his book of the same name, Goleman (2006: 11) concisely explains SI as "being intelligent not just about our relationships but also in them" (italics in the original). However, Goleman warns that 
some caution is necessary here as SI can be used manipulatively by those out to trick or sell people something. Therefore, he suggests that it needs to be stated explicitly that SI is the skill of managing interpersonal relationships for genuine humanistic, caring, healthy social relationship purposes as opposed to any manipulative, unhealthy, self-serving purposes (Goleman 2006). A key reason for the central importance of SI are findings from neuroscience that humans 'are wired to be social' (Lieberman 2013) with human brains designed for cooperation, collaboration and success in social groups (Decety and Cacioppo 2015; see also Kelly, this volume).

A problem in the field of education is that the terms EI and SI are not the only ones that abound in this area. Indeed, the 'smorgasbord' (Humphrey 2013: 24) of definitions and constructs in the field has caused many difficulties both in empirical measurement and design, as well as in conceptual and theoretical discussions. Some key related terms include emotional literacy (Spendlove2008), social and emotional learning (Humphrey 2013), and social and emotional competence (Denham and Brown 2010). We have chosen to focus on the terms EI and SI specifically due to their familiarity and hence accessibility for teachers, who are the audience we wish to investigate as well as the intended recipients of our research.

\subsection{Why do we need emotional and social intelligence in education?}

One of the key premises underlying this chapter is our conviction in the importance of EI and SI in educational contexts, not only for learners but also for teachers. Fundamentally, teaching is a social activity built upon relationships. Bahman and Maffini (2012: 13) describe how "one teacher can help a child love school; another can make a child hate school. It all depends on our relationships with the children". Underhill (2013: 204) suggests that teacher expertise is composed of "knowledge of the topic, skill with classroom methods and competence with interand intrapersonal relationships and the psychological learning atmosphere of the group". $\mathrm{He}$ highlights the importance of the socio-emotional skills of teachers and the importance of their sensitivities towards the relational aspects of classroom life. Indeed, in Hattie's (2009) famous meta-analysis of key factors in successful teaching and learning, teacher-student relationships are just outside the top ten out of 138 factors coming in at place 11 in the list of key influences on learning. In addition, research on the social neuroscience of education also indicates that healthy and secure relationships lie at the heart of effective education (Cozolino 2013). As Furrer, Skinner, and Pitzer (2014: 102) summarise, "an extensive body of research suggests the 
importance of close, caring teacher-student relationships and high quality peer relationships for students' academic self-perceptions, school engagement, motivation, learning, and performance" (italics in the original).

Thus, managing the relationships in the classrooms is a key responsibility for teachers although it is rarely addressed in teacher training. A major element contributing to positive relationships is the ability to read and interpret one's own and others' emotions (see also Gregersen and MacIntyre, this volume). As Jennings and Greenberg (2009: 493) claim, social and emotional competences are "an important contributor to the development of supportive teacher-student relationships" as well as other desirable outcomes such as a healthy classroom climate and effective classroom management. Powell and Kusuma-Powell (2010: 6) explain that, "teaching is an interpretative activity", requiring teachers to interpret students' actions, facial expressions, moods and emotions hundreds of times each day. As both teachers and learners are emotional beings, classroom life generally is permeated throughout with emotions; teachers have to engage in 'emotional labour' regulating, managing and controlling their own emotions throughout their working day (King 2016; Tsang 2011) and responding to the emotional outbursts and moods of their learners as they seek to create a positive and cooperative working climate. Within the classroom, teachers themselves serve as the central hub for classroom interaction and subsequently their emotional well-being is vital for an "emotionally healthy classroom" (Frenzel and Stephens 2013: 35). This means that teachers and the self-regulation of their own emotions is as important as how they interact with others. This is evinced by the fact that most intervention programmes designed to promote EI all seem to agree on the importance first of understanding one's own emotions, before one is able to reflect on or interpret the emotions of others (e.g., Bahman and Maffini 2012; Cohen 2001; Denham and Brown 2010; Morris and Casey 2006). Indeed, several studies have indicated that teachers can benefit from strong EI to help them cope with the emotional demands of contemporary classrooms (Day and Gu 2009; Elias and Arnold 2006; Powell and Kusuma-Powell 2010). As teachers and their well-being are important for the quality of classroom life, it is vital that teachers are supported in regulating and managing their own emotions both for their own wellbeing as well as that of their learners. Teaching is known to be a complex, highly stressful profession with strong emotional demands (see, e.g., Day and Gu 2010; King 2016; Tsang 2011; Zembylas 2005) and research is beginning to suggest that various aspects of EI can help reduce teacher stress levels and promote job satisfaction (see, e.g., Brackett et al. 2010; Chan 2006; Jennings and Greenberg 2009).In light of these understandings about the quality of 
classroom life and central importance of interpersonal relationships, it soon becomes apparent just how significant the EI and SI of the teacher are.

\subsection{Emotional and social intelligence in educational research}

In general education, EI and SI have been examined in different contexts, with the largest body of research considering social and emotional aspects of learning from the learner's perspective. In particular, a whole field has emerged entitled 'social and emotional learning' (SEL). SEL typically focuses on learners but examining the definition, its relevance for teachers and EI/SI seem equally pertinent.

"The social aspect of SEL indicates a concern for fostering positive relationships with others, such as peers, teachers, and family members. This part of SEL reflects interpersonal development. The emotional aspect of SEL indicates a concern for fostering self-awareness or self-knowledge, especially involving emotions or feelings, but also by implication, the cognitions or thoughts that are connected to our emotions. This part of SEL essentially reflects intrapersonal development. The learning aspect of SEL implies that both social and emotional growth and adjustment can be taught and learned through instruction, practice, and feedback." (Merrell and Gueldner 2010: 6-7) (italics in the original)

In other words, the social and emotional dimensions are centrally interconnected with each other and both can be learned through directed interventions. Indeed, there has been a considerable body of research examining SEL interventions. For example, it has been shown that SEL programmes can support students' social and emotional development (Allen, Maccann, Matthews, and Roberts 2014; Durlak et al. 2011) and their academic success (Denham and Brown 2010; Merrell and Gueldner 2010). In their meta-analytic study on schoolbased interventions on SEL, Durlak et al. (2011) found that SEL programmes positively influenced students' EI and SI as well as their attitudes towards self, others, and the school; students developed prosocial behaviours, were more motivated to learn, and were more willing to discuss their concerns rather than internalising them. Zins and Elias (2006: 3) suggest that academic gains are possible too "because social, emotional, and academic growth are interdependent, the result is synergistic progress in all of these areas". Summarising work on intervention studies, Humphrey (2013: 113) concludes that "larger gains are seen in proximal (e.g., social and emotional skills) variables than distal (e.g., academic performance) variables". However, he cautions that there is much potential variation in how studies are conducted, variables measured, and how interventions are actually carried out in practice. 
One important consideration has been whether only those with deficiencies in SEL areas profit from intervention programmes or whether all participants can benefit, albeit potentially to differing degrees, and there seems a lack of consensus in the field at present (Humphrey 2013). Our view is that given the centrality of emotions and relationships to all that we do as human beings, but especially as teachers, we feel that we at the least need to better understand the potential gains that can be made from SEL interventions not only for learners, but also teachers. Whilst some teachers may begin with stronger skills than others in this respect, we feel that everyone always has the potential to still improve on their current abilities (see, e.g., Powell and Kusuma-Powell 2010).

In empirical studies on EI, research has shown that emotionally intelligent teachers are better able to create classroom conditions that increase students' motivation to learn and decrease student misconduct (Nizielski, Hallum, Lopes, and Schütz 2012); are in a position to acknowledge their own emotions as they experience them (Corcoran and Tormey 2012a, 2012b, 2013), and are aware of ways of coping with their anxiety and their students' anxiety and of creating a positive, low-anxiety classroom atmosphere (Jennings and Greenberg 2009; Meyer and Turner 2007).

With reference to SI among teachers, there have been significantly fewer research studies conducted than those on EI. This could be due to the perceived overlap in the terms which has led in some cases to facets of SI being subsumed within EI studies. However, SI is especially important for teachers in order to manage their work relationships with learners and colleagues effectively and efficiently. Perhaps even more importantly, good SI skills would help teachers in reading the classroom climate and promoting positive group dynamics and a supportive rapport between teacher and learners. Studies focusing specifically on SI have found that socially intelligent teachers are better able "to read nonverbal cues or make accurate social inferences" (Brown and Anthony 1990: 197) and can foreground the value of peer support and collaboration (Albrecht 2006).It can be expected that socially intelligent teachers are able to cater for students' individual differences and needs and also to work at engendering the positive social relationships needed in classrooms.

\subsection{Emotional and social intelligence in language teaching}

Although EI and SI have a key role to play in education generally given the inherently interpersonal and social nature of any kind of learning and teaching, it soon becomes apparent 
that foreign language education in particular might greatly benefit from these two competencies perhaps more so than almost any other educational domain. This is because contemporary foreign language learning and teaching is largely based on communicative activities which typically involve collaboration and cooperation among students, and also between students and the teacher. In this respect, Dörnyei and Murphey (2003: 1) argue that, "group dynamics is probably one of the most - if not the most - useful subdisciplines in the social sciences for language teachers" (italics in the original).

Being able to see the world from someone else's perspective plays a key role in promoting intercultural competence (Spencer-Oatey and Franklin 2014), which is one of the pillars of communicative competence. 'Ethnocultural empathy' is defined as "feeling, understanding, and caring about what someone from another culture feels, understands and cares about" (Rasoal et al. 2011: 8). Within the context of globalisation and English as an International Language (Crystal 2003) where learners may use their English with people from across the globe rather than with interlocutors from a specific target culture, learners need non-culturespecific intercultural competences such as those typical within EI and SI. Self-awareness and empathy, which are key elements of EI and SI, can facilitate interpersonal and intercultural understanding and help learners to appreciate other cultural perspectives, increasing tolerance and fostering an openness to others. "Seeing things from another's perspective breaks down biased stereotypes, and so breeds tolerance and an acceptance of differences. These capacities are ever more called on in our increasingly pluralistic society, allowing people to live together in mutual respect and creating the possibility of productive discourse" (Goleman 1996: 285). Naturally, such skills are particularly important in contemporary and increasingly multicultural classrooms across the globe.

Although there has been increasing recognition of the central importance of relationships and emotions in the language learning and teaching processes (Benesch 2012; Dewaele 2010; Dörnyei and Murphey 2003; Golombek and Doran 2014; Golombek and Johnson 2004; Imai 2010; Mercer 2016; Tassinari 2015; Williams, Mercer, and Ryan 2015), research specifically into the competences of EI and SI of either teachers or learners remains scarce. The few studies that do exist in the field have centred on EI. For example, with regard to learners, research has examined the relationship between EI and learners' levels of anxiety. Dewaele, Petrides, and Furnham (2008) conducted a large-scale online survey with 464 adult multilinguals and found that highly emotionally intelligent participants reported lower levels of communicative and 
foreign language anxiety. Similarly, in a study with 510 Chinese EFL students, Shao, Yu and Ji (2013) found a significant negative correlation $(r=-0.681, p<0.01)$ between students' EI and foreign language anxiety. Oz, Demirezen, and Pourfeiz (2015) looked at the relationship between perceptions of EI and attitudes towards foreign language learning among 159 Turkish university EFL learners. Their findings showed that EI and attitudes towards foreign language learning were positively correlated, and that self-awareness and self-regulation of emotions were the strongest predictors of overall EI.

With regard to language teachers, Moafian and Ghanizadeh (2009) found a significant positive correlation between Iranian EFL teachers' EI and their self-efficacy. In a case study with a preservice teacher from the United States, Gregersen et al. (2014) found that their participant continuously and effectively used her EI in an attempt to identify, understand and manage her emotions whilst teaching. In the context of teacher training, the authors conclude that EI can play an important role in facilitating language teachers' self-development and their ability to effectively self-regulate their emotions during teaching and training. Recently, in SLA, there has been an upsurge of interest in positive psychology and the constructs associated with this perspective, leading to increased research into the social and emotional dimensions of language learning (see, e.g., MacIntyre et al. 2016). For example, King (2015) explored the concept of 'emotional labour' during English language teaching within a Japanese university. Emotional labour refers to the construction and suppression or regulation of emotions during interpersonal encounters (see also: Hargreaves 2000; Tsang 2011; Zembylas 2007). Using semi-structured interviews with five experienced teachers, King (2015) found that teachers managed to regulate their emotions during teaching and found ways to increase student motivation and help students to achieve their learning goals.

In contrast to EI, SI appears to be entirely absent from the research landscape to the best of our knowledge. One possible reason for this might be due to researchers subsuming SI as part of EI. However, elements of SI do appear in part under more well-established concepts within SLA such as group dynamics, teacher-student rapport, and collaborative learning. A relevant study in the field, which has indirectly touched upon SI by looking at emotions in collaborative learning, is Imai (2010). The researcher conducted two case studies with two different groups of Japanese university EFL learners working together outside of class in order to prepare for an oral group presentation in English. The findings showed that emotions should not be simply viewed as an intrapsychological construct within SLA but as socially and interactively 
constructed acts through which learners negotiate, support and help each other towards appropriating learning goals. In a theoretical paper, Mercer (2016) has argued for the importance of empathy, which is a key component of SI, in SLA. She argues that the field is undergoing a 'relational turn' and that relationships need to be more often the focus of research and the unit of analysis.

We therefore conclude that, given the collaborative and communicative nature of foreign language learning and teaching and the need for positive interpersonal skills in intercultural communication, both EI and SI are particularly important skills for language teachers and learners. It is thus perhaps surprising that teacher education programmes do not explicitly address these core competencies. One reason for this could be the absence of focused research to inform such training but also perceptions about the other priorities of teachers who are often keen to have technical methods and tools, as opposed to what are perhaps perceived by some as less essential 'soft skills'. Yet, for us, we feel these are exactly the core skills any teacher but especially young language teachers need to not only cope but to 'thrive' in their jobs (Castle and Buckler 2009: 4).

\subsection{Teacher training and EI/SI}

A key question for teacher training is the extent to which EI and SI skills can be developed. Firstly, although views on whether EI is defined as an ability, trait, knowledge, or all three vary (Nelis et al. 2009), evidence from intervention studies suggests that the competences inherent in the EI and SI models we have chosen to focus on are malleable, at least to some degree, and can be promoted through training (see, e.g., Brackett and Katulak 2006; Nelis et al. 2009; Zins et al. 2004). This is a key point which suggests that it is feasible to expect that training programmes including a well designed series of components to address teachers' EI and SI would have the potential to make a difference, although clearly more rigorous research is needed to evaluate such programmes and their design. As Goleman (1998: 244) says, "technical training is easy compared to developing emotional intelligence". Therefore, serious consideration needs to be given to the design of programmes such as whether teaching is explicit or implicit, intense or spaced, how materials are designed, sequenced and delivered, and so on (Humphrey 2013).

For our purposes, we simply wish to argue that "social-emotional skills are a key part of personal development and job success" (Reissman 2006: 82). As such, these skills are 
especially important for new teachers who are at greatest risk of burnout and dropping out of their chosen profession due to unmanageable perceptions of stress. In their extensive study of teachers' lives, Day and Gu (2010: 36) argue that, “experience and research, then, suggest that a dichotomy between promoting technical competence and personal growth in professional learning is false, and that ignoring the contributions of teachers' sense of emotional wellbeing to their capacities to teach to their best is foolish". They conclude that supporting teachers in their emotional and personal competences should become a key part of teacher training and professional development and we would strongly support that suggestion, whilst also acknowledging the challenges that this could potentially entail.

\section{Method}

The review of the literature on EI and SI in the fields of education and language teaching raises various questions, some of which we seek to address through this study. In particular, our first steps on our journey towards developing a plan for integrating EI and SI into teacher training is to gain an overview of the state of the field, to understand these constructs and whether general EI/SI are suitable constructs or whether we need to think of them in more domainspecific terms. We also want to try to understand what kinds of individual variation there might be according to a series of demographic factors and dimensions specific to language learning. Our RQs guiding the study were:

RQ1. What levels of EI/SI (trait and educational-context-specific) do EFL teachers across the globe in different educational settings have?

RQ2. Is there an educational-context-specific EI/SI as distinct to trait EI/SI?

RQ3. Are there differences in EFL teachers' levels of EI/SI according to various demographic factors?

\subsection{Participants}

EFL teachers $(N=890)$ from diverse contexts participated in the present study which used an online questionnaire. The participants teach in a wide range of educational contexts across the globe working at different educational levels (including primary, secondary and tertiary) and with varying levels of teaching experience and experiences of working abroad. The participating teachers' mean age was $39.95(S D=10.56)$, the mean number of years of teaching experience was $14.81(S D=9.63)$ and the mean number of different countries the participants have worked in was $2.98(S D=2.64)$. Table 3.1 below summarises the demographic 
information and descriptive statistics for teachers in terms of the geographical area where they currently teach, their overseas teaching experiences, gender, educational level they teach at and highest level of academic qualification.

Table 3.1. Descriptive statistics for participants in the study

\begin{tabular}{|c|c|}
\hline Geographical area/Continent & $\begin{array}{l}\text { Europe: } 292 \\
\text { North America: } 14 \\
\text { South America: } 13 \\
\text { Central America: } 8 \\
\text { Asia: } 410 \\
\text { Middle East: } 104 \\
\text { Africa: } 23 \\
\text { Oceania: } 14\end{array}$ \\
\hline Overseas teaching experience & $\begin{array}{l}\text { Yes: } 297 \\
\text { No: } 572\end{array}$ \\
\hline Gender & $\begin{array}{l}\text { Male: } 299 \\
\text { Female: } 555 \\
\text { Prefer not to disclose: } 15\end{array}$ \\
\hline Educational level of present teaching & $\begin{array}{l}\text { Primary school: } 248 \\
\text { Secondary school: } 469 \\
\text { Post-secondary education: } 528\end{array}$ \\
\hline Highest level of academic qualification & $\begin{array}{l}\text { School-leaving certification: } 16 \\
\text { Bachelor's degree: } 269 \\
\text { Master's degree: } 436 \\
\text { PhD: } 99 \\
\text { Other: } 52\end{array}$ \\
\hline
\end{tabular}

\subsection{Instrument}

For the purposes of the present study, we developed a new quantitative data collection instrument, the EFL Teachers' Emotional and Social Intelligence Questionnaire (EFL TESIQ), which was found to be highly reliable ( 80 items; $\alpha=.89$ ) and consists of three main sections: 
- Section 1: Biodata

This section includes questions on participant information such as current teaching context, teaching experience in present context and overseas, age, gender, educational level of present teaching and level of qualification.

- Section 2: General EI and SI

This section comprises 40 self-reported statements which measure participants' level of agreement through a 7-point Likert scale. These items are further divided into two categories as follows:

Category 1: Trait Emotional Intelligence. This category includes 20 items $(\alpha=.82)$ which are based on the Trait Emotional Intelligence Questionnaire Short Form (TEIQue-SF; Petrides and Furnham 2006). The items in this subscale represent the five main components of EI as defined by Goleman (1996), namely, self-awareness, selfregulation, motivation, empathy and social skill. Although items were drawn from TEIQue-SF, which is an instrument with high internal consistencies ( $\mathrm{a}=.84$ for males, $\mathrm{a}=.89$ for females; Petrides and Furnham 2006), it was decided to rely on Goleman's (1996) five components of EI to select specific items as TEIQue-SF did not make clear which aspects of EI are assigned to its different items. In addition, the original TEIQueSF consisted of 30 items which we reduced to 20 given that we felt that certain items were tautological and difficult for non-native speakers of English. Example items from the final questionnaire include I am not always able to recognise what emotion I'm feeling (self-awareness), I usually find it difficult to control my emotions (selfregulation), I normally tend to be optimistic (motivation), I'm good at predicting how someone feels (empathy) and I can work effectively with other people (social skill).

Category 2: Trait Social Intelligence. This category includes 20 items $(\alpha=.79)$ which are drawn from the Interpersonal Competence Questionnaire (ICQ; Buhrmester, Furman, Wittenberg, and Reis 1988).The items here represent the five components of interpersonal or social intelligence as defined by Buhrmester et al. (1988), namely, initiation, negative assertion, disclosure, emotional support, and conflict management. The internal consistency of the ICQ subscales was high in Buhrmester et al. (1988); the alpha coefficient ranged from .77 to .87 . The EFL TESIQ items were phrased slightly 
differently in the present study in order to match the statements of TEIQue-SF and because it was thought best to use I-statements for comprehensibility. For example, item 1 Asking or suggesting to someone new that you get together and do something, e.g., go out together was changed to I typically ask or suggest to someone new that we get together and do something, e.g., go out together. The original ICQ comprises 40 statements. Again these were reduced to 20 in order to focus only on those items that were most relevant for a professional context. We also intended to maintain coherence among different subscales within the entire EFL TESIQ with regard to number of items and thus avoid administering a long survey, which might have led to high attrition rates. For coherence across the different scales in the final questionnaire, it was also decided to change the rating scale to a 7-point Likert scale as opposed to the original 5-point one. Finally, some individual wording was altered to make it more readily comprehensible for different respondents in a variety of contexts where English may be their L2. Examples of Trait Social Intelligence items include I consider myself an easy person to get to know (initiation), I can confront close friends when they have broken a promise (negative assertion), I don't tell a close friend things about myself that I'm embarrassed about (disclosure), I am a good and sensitive listener for a friend who is upset (emotional support) and I am usually able to put negative feelings aside when having an argument with a close friend (conflict management).

- Section 3: Domain-specific EI and SI

This section comprises 40 self-reported statements which measure participants' level of agreement through a 7-point Likert scale. These items were designed to mirror the first two scales but in more specifically, clearly educational-related contexts. They are divided into two categories as follows:

Category 1: Educational-context-specific Emotional Intelligence. This category includes 20 items $(\alpha=.85)$ specific to an educational setting which were adapted from TEIQue-SF (Petrides \& Furnham 2006). Again, the items reflected Goleman's five components of EI but in domain-specific terms. Examples of items include: I know what my strengths are as a teacher (self-awareness), I usually find it difficult to control my emotions in the classroom (self-regulation), I am able to develop a positive rapport with my groups of learners (social skill). 
Category 2: Educational-context-specific Social Intelligence. This category consists of 20 items $(\alpha=.70)$ specific to an educational setting adapted from Buhrmester et al. (1988) and mirroring their five components of interpersonal competence. Examples of items include: While teaching I tell learners stories from my own life when appropriate (disclosure), I'm usually able to attentively listen to a colleague complain about problems he or she is having (emotional support), If students are arguing with each other, I am able to intervene and ensure both parties make up satisfactorily (conflict management).

A first draft of the EFL TESIQ was piloted with a small sample of EFL teachers in September 2015. The pilot questionnaire yielded high reliability ratings, and the meta-feedback led to changes only in layout and design of the online representation of the questionnaire.

\subsection{Data collection procedure}

EFL TESIQ was distributed via Survey Monkey in October 2015. The link was sent to teachers at all educational levels through personal contact networks, as well as lists of national and international EFL teacher associations across the globe. For ethical purposes, an 'opt-in' approach was adopted and informed consent was assumed on voluntary participation and completion of the questionnaire. An introductory text was included, which briefly summarised the study, assured participants' anonymity and confidentiality and acknowledged the external sources that were used to draw ideas for different items. In terms of reciprocity, after completing the questionnaire, a useful website addressing EI and SI amongst other psychological constructs in respect to education was recommended to participants if they were interested in finding out more about positive psychology in education (http://greatergood.berkeley.edu/). As this is the first stage in a three-stage study, at the end, we also asked for volunteers who would be willing to share their name and email address with us and take part in the follow-up classroom observations and individual interviews planned for later stages of the project.

\subsection{Data analysis}

The data were analysed using SPSS version 19.0. The first step in data processing involved quantifying the data and reversing negatively worded items. Descriptive statistics (i.e., mean, standard deviation, minimum, maximum) were used to present participants' EI and SI scores. 
Pearson product-moment correlations were performed in order to examine the relationship between trait EI, trait SI, educational-context-specific EI, and educational-context-specific SI. Independent samples t-tests were used in order to examine gender differences among levels of EI and SI. In addition, a multiple regression analysis was conducted in order to further test the relationships among EI and SI and a range of demographic variables such as participants' age, gender, teaching experience, overseas experience, educational level of current teaching, and qualification.

\section{Results}

The participants' ratings of individual items were added up in order to calculate their total trait EI, trait SI, educational-context-specific EI, and educational-context-specific SI. Overall, the findings suggested that the participating teachers were highly emotionally and socially intelligent. The descriptive statistics for their levels of EI and SI are summarised in Table 4.1.

Table 4.1. Descriptive statistics for participants' levels of EI and SI

\begin{tabular}{|l|c|c|c|c|}
\hline & Trait EI & Trait SI & $\begin{array}{c}\text { Educational- } \\
\text { context-specific } \\
\text { EI }\end{array}$ & $\begin{array}{c}\text { Educational- } \\
\text { context-specific } \\
\text { SI }\end{array}$ \\
\hline$M$ & 107.36 & 100.30 & 111.86 & 102.84 \\
\hline$S D$ & 12.99 & 13.32 & 12.47 & 11.40 \\
\hline Minimum & 20 & 20 & 20 & 20 \\
\hline Maximu & 140 & 140 & 140 & 140 \\
\hline
\end{tabular}

Pearson product-moment correlations between the different categories of EI and SI were also examined. The strongest significant positive correlation was found between trait EI and educational-context-specific EI. There was also a significant positive correlation between trait SI and educational-context-specific SI. Moderate to high significant positive correlations were also found between trait EI and trait SI, trait EI and educational-context-specific SI, trait SI and educational-context-specific EI, and educational-context-specific EI and educational-contextspecific SI. Table 4.2 presents the correlation matrix.

Table 4.2. Correlations among the two different types of EI and SI 


\begin{tabular}{|l|c|c|c|c|}
\hline & Trait EI & Trait SI & $\begin{array}{c}\text { Educational- } \\
\text { context-specific } \\
\text { EI }\end{array}$ & $\begin{array}{c}\text { Educational- } \\
\text { context-specific } \\
\text { SI }\end{array}$ \\
\hline Trait EI & 1.00 & 1.00 & 1.00 & \\
\hline Trait SI & $.68^{* *}$ & $.60^{* *}$ & & \\
\hline $\begin{array}{l}\text { Educational- } \\
\text { context-specific } \\
\text { EI }\end{array}$ & $.79 * *$ & $.70^{* *}$ & $.69 * *$ & 1.00 \\
\hline $\begin{array}{l}\text { Educational- } \\
\text { context-specific } \\
\text { SI }\end{array}$ & $.60^{* *}$ & & & \\
\hline
\end{tabular}

**. Correlation is significant at the 0.01 level (2-tailed).

The correlation analysis revealed that the participating teachers' trait EI was similar to their educational-context-specific EI. Similarly, their trait SI was similar to their educationalcontext-specific SI, thus leading us to conclude that there is no statistical difference between the trait and context-specific constructs. Given these strong links and the fact that no difference emerged between trait and context-specific EI and SI, we then examined the relationships between various demographic factors and trait EI and SI. Specifically, gender differences were found for participants' levels of trait EI and trait SI, with female participants scoring slightly higher than male participants. Table 4.3 summarises the differences in mean scores for male and female teachers. All differences were statistically significant at $p<.05$.

Table 4.3. Differences according to gender

\begin{tabular}{|l|c|c|}
\hline & Trait EI & Trait SI \\
\hline Male & $M=104.30$ & $M=97.18$ \\
\hline & $S D=13.98$ & $S D=15.06$ \\
\hline Female & $M=108.74$ & $M=101.84$ \\
\hline & $S D=12.2$ & $S D=12.13$ \\
\hline$t$-tests & $t(361)=3.845, \mathrm{p}<.05$ & $t(334)=3.792, \mathrm{p}<.05$ \\
\hline
\end{tabular}

In terms of geographical areas, there were mean differences across regional groups and this raises questions about the cultural appropriacy of the EI and SI scales. However, this finding 
should be interpreted with caution as the mean differences might only be related to the regional groups that were picked up in the current measurement. Table 4.4 shows the descriptive statistics for trait EI and trait SI according to the continent/geographical area where the participating teachers currently teach.

Table 4.4. Descriptive statistics for trait EI/SI according to geographical area

\begin{tabular}{|c|c|c|c|}
\hline & Geographical area & $M$ & $S D$ \\
\hline \multirow[t]{8}{*}{ Trait EI } & Europe & 108.9402 & 11.41476 \\
\hline & North America & 111.9091 & 7.99318 \\
\hline & South America & 112.3333 & 6.89202 \\
\hline & Central America & 108.5000 & 12.58306 \\
\hline & Asia & 92.1303 & 13.49438 \\
\hline & Middle East & 81.3056 & 15.41687 \\
\hline & Africa & 106.1667 & 18.07476 \\
\hline & Oceania & 103.0909 & 12.65270 \\
\hline \multirow[t]{8}{*}{ Trait SI } & Europe & 100.2747 & 11.45163 \\
\hline & North America & 99.2727 & 12.43456 \\
\hline & South America & 114.1818 & 6.99740 \\
\hline & Central America & 99.0000 & 10.67708 \\
\hline & Asia & 100.4661 & 13.57180 \\
\hline & Middle East & 73.8261 & 11.90576 \\
\hline & Africa & 99.6000 & 10.12368 \\
\hline & Oceania & 98.6000 & 14.18293 \\
\hline
\end{tabular}

Correlation tests on the relationship between age, teaching experience, overseas experience, and trait EI and SI, also revealed significant results (see Table 4.5). In particular, there was a high positive correlation between the participants' age and their trait $\mathrm{EI}(r=.72, p<.01)$. Additionally, a positive moderate correlation was found between teaching experience and trait $\mathrm{EI}(r=.54, p<.01)$, overseas experience and trait $\mathrm{EI}(r=.50, p<.05)$, and overseas experience and trait SI $(r=.43, p<.05)$. A very weak correlation was found between trait SI and teaching experience $(r=.12, p<.01)$, and the correlation between trait SI and age was not statistically significant. 
Table 4.5. Correlations between trait EI and SI, and age, teaching experience, and overseas experience

\begin{tabular}{|l|c|c|}
\hline & Trait EI & Trait SI \\
\hline Age & $.720^{* *}$ & .130 \\
\hline Teaching experience & $.541^{* *}$ & $.120^{* *}$ \\
\hline Overseas experience & $.506^{*}$ & $.431^{*}$ \\
\hline
\end{tabular}

*. Correlation is significant at the 0.05 level (2-tailed).

**. Correlation is significant at the 0.01 level (2-tailed).

The next step was to evaluate the correlates as predictors in a multiple regression and, thus, multiple regression analyses were utilised in order to gauge the predictive power of demographic variables on trait EI and trait SI. The predictors entered into the regression equation were age, gender, teaching experience, overseas experience, educational level of present teaching, and highest academic qualification. The results of the multiple regression analyses for trait EI and trait SI are presented in Tables 4.6 and 4.7 respectively.

Table 4.6. Multiple regression analysis for trait EI $\left(R^{2}=.66\right)$

\begin{tabular}{|l|c|c|c|}
\hline & $\beta$ & $t$-statistic & $p$-value \\
\hline Gender & .259 & 3.956 & .000 \\
\hline Age & .172 & .562 & .000 \\
\hline Teaching experience & .127 & .970 & .000 \\
\hline Overseas experience & .110 & 1.617 & .000 \\
\hline Qualification & .069 & 1.035 & .302 \\
\hline $\begin{array}{l}\text { Educational level of } \\
\text { present teaching }\end{array}$ & .059 & .757 & .550 \\
\hline
\end{tabular}

Table 4.7. Multiple regression analysis for trait SI $\left(R^{2}=.66\right)$

\begin{tabular}{|l|c|c|c|}
\hline & $\beta$ & $t$-statistic & $p$-value \\
\hline Gender & .262 & 3.953 & .000 \\
\hline Age & .135 & 1.068 & .287 \\
\hline Overseas experience & .125 & .957 & .000 \\
\hline Qualification & .118 & .957 & .000 \\
\hline
\end{tabular}




\begin{tabular}{|l|c|c|c|}
\hline Teaching experience & .113 & .640 & .000 \\
\hline Educational level of & .051 & .675 & .500 \\
present teaching & & & \\
\hline
\end{tabular}

These results elaborate on the correlations reported in Table 4.5. Considering the demographic factors as a group, gender made the strongest contribution to both trait EI and SI (i.e., $\beta=.259$ for trait EI, $\beta=.262$ for trait SI). In the case of trait EI, age was the second strongest predictor $(\beta=.172)$, followed by teaching experience $(\beta=.127)$ and overseas experience $(\beta=.110)$. The other predictors, qualification and educational level of present teaching, did not add additional prediction. A rather different picture emerged with trait SI. After gender, overseas experience $(\beta=.125)$ had a significant level of prediction, followed by qualification $(\beta=.118)$ and teaching experience $(\beta=.113)$. Finally, age and educational level of present teaching were not significant predictors of trait SI.

\section{Discussion}

The results of this survey raise some interesting questions. Firstly, one of our aims was to investigate whether the participating teachers' educational-context-specific EI and SI are distinct from their trait EI and SI. The strong positive correlations between trait EI and domainspecific EI, and similarly between trait SI and domain-specific SI, showed that the trait and domain-specific constructs were not statistically different and therefore, the constructs of trait EI and SI could be used as appropriate measurements in relation to educational contexts. The findings also revealed a number of relationships between variables. As can be expected from other research (Bar-On 2006; Corcoran and Tormey 2012a, 2013; Petrides, Furnham, and Martin 2004), we too found gender differences in levels of EI and SI with females scoring higher on these competences. Many reasons have been proposed for this difference including socialisation processes and the suggestion that males and females may vary as to whether they examine things in more holistic or more analytical ways (see Baron-Cohen 2003; Denham, Bassett, and Wyatt 2010; Garner, Robertson, and Smith 1997; Garside and Klimes-Dougan 2002). Naturally, there also remains the potential for individual variation across and within genders, and care must be taken not to overlook different individual capacities for EI (Humphrey 2013; Mayer, Salovey, and Caruso 2008). 
Other interesting findings concerned the role of experience as a teacher and in working overseas as well as with age and EI. It would seem that the more experienced an individual is, the more life experiences they have to draw on, perhaps the more fine-tuned their EI competences become. This suggests there is a particular need to support less experienced preservice teachers who may have lower levels of EI and SI and may need more training in developing their skills in these areas to manage their own emotions and help them promote positive group dynamics and rapport in class more easily. There were also some differences across geographical regions in levels of EI and SI, which might raise questions about the cultural appropriacy of the scales used in this questionnaire. One reason for this are findings from research in fields other than language education, which have shown that the processing of emotional information might depend on subtle cultural differences among participants (see, e.g., Fernández-Berrocal et al. 2005; Ghorbani et al. 2002; Shipper et al. 2003). The present study also suggests that the processing and socialisation of emotions could be culture-specific, and thus emotional understanding and social processes in different cultures may need to be taken into account when interpreting questionnaire data and suggesting interventions (Zeidner, Matthews, and Roberts 2001).

From our examination of the literature, we conclude that there are good reasons to suggest including an EI/SI element in teacher training programmes, yet, we are also aware of the potential problems this may entail. One concern could be that there is not sufficient time for such skills within packed training programmes where such skills might not be seen as a priority. However, as Weinstein (1999 in Jennings \& Greenberg 2009: 507) explains, understandings of teaching have shifted over the years moving from cognitive, management perspectives that rest on training teachers with a 'bag of tricks' towards more reflective practices which are based on caring relationships that foster learner-centred and self-regulatory approaches in which EI and SI are cornerstone competences. Another set of problems concerns how best in practical terms to train teachers for these skills. Although there seems to be good reason for optimism, there remains an absence of studies examining actual focused interventions in teacher training, generally but especially in SLA. Ideally, we would like to be able to base proposed programmes on rigorous research, but, first of all, more research is needed to examine whether, to what extent, under what conditions, and in what ways interventions can benefit participants in the field of SLA. In particular, researchers will need to grapple with how EI and SI are defined and measured in order to facilitate comparisons across studies as well as the relative transferability of EI and SI skills across cultural settings. As Weare (2004: 19 cited in Humphrey 2013: 23) 
states, "deciding what goes on a list of emotional and social competences cannot be value-free, culture-free or an apolitical exercise". In addition, we also need to know more about what kinds of local level institutional supports are necessary to ensure the success of such training programmes as well as the potential effects of other factors including personal individual differences, attitudes, and motivations, duration of training, prescriptiveness of training, resources available, planning involved etc. (see, e.g., Humphrey 2013).

\section{Conclusion}

We are not suggesting in this chapter that EI and SI are magical panacea for the challenges facing language teachers across the globe, but they do represent key $21^{\text {st }}$ century life skills that can enhance teachers' relationships with their learners, colleagues as well as within intercultural encounters in class or beyond. In addition, research indicates that teachers with strong EI and SI might benefit personally as these skills have been shown to protect them from burnout and enhance their professional lives. Importantly, their learners will profit too from having teachers who serve as excellent role models to emulate as well as from the positive teacher-student rapport and classroom atmosphere such teachers can generate. Therefore, despite some reservations and need for caution as we seek to learn more about these constructs in our field and how best to work with them, we feel their potential importance should ensure they are put on the top of the research agenda and considered as core components of pre-service teacher training programmes. 


\section{References}

Albrecht, K. (2006). Social intelligence: The new science of success. San Francisco, CA: Jossey-Bass.

Allen, V., Maccann, C., Matthews, G., \& Roberts, R. D. (2014). Emotional intelligence in education: From pop to emerging science. In R. Pekrun \& L. Linnenbrink-Garcia (Eds.), International handbook of emotions in education (pp. 162-182). New York: Routledge.

Bahman, S., \& Maffini, H. (2012). Developing children's emotional intelligence. London: Continuum.

Bar-On, R. (2006). The Bar-On model of emotional-social intelligence (ESI). Psicothema, 18(suppl.), 13-25. 
Baron-Cohen, S. (2003). The essential difference: The truth about the male and female brain. New York: Basic Books.

Benesch, S. (2012). Considering emotions in critical English language teaching: Theories and praxis. London: Routledge.

Brackett, M. A., \& Katulak, N. (2006). The emotionally intelligent classroom: Skill-based training for teachers and students. In J. Ciarrochi \& J. D. Mayer (Eds.), Improving emotional intelligence: A practitioner's guide (pp. 1-27). New York, NY: Psychology Press/Taylor \& Francis.

Brackett, M. A., Palomera, R., Mojsa-Kaja, J., Reyes, M. R., \& Salovey, P. (2010). Emotionregulation ability, burnout, and job satisfaction among British secondary-school teachers. Psychology in the Schools, 47(4), 406-417.

Brown, L. T., \& Anthony, R. G. (1990). Continuing the search for social intelligence. Personality and Individual Differences, 11(5), 463-470.

Buhrmester, D., Furman, W., Wittenberg, M. T., \& Reis, H. T. (1988). Five domains of interpersonal competence in peer relationships. Journal of Personality and Social Psychology, 55(6), 991-1008.

Castle, P., \& Buckler, S. (2009). How to be a successful teacher: Strategies for personal and professional development. Thousand Oaks, CA: Sage.

Chan, D. W. (2006). Emotional intelligence and components of burnout among Chinese secondary school teachers in Hong Kong. Teaching and Teacher Education, 22(8), 10421054.

Cohen, J. (2001). Social and emotional education: Core concepts and practices. In J. Cohen (Ed.), Caring classrooms/intelligent schools: The social emotional education of young children (pp. 3-29). New York: Teachers College Press. 
Corcoran, R. P., \& Tormey, R. (2012a). How emotionally intelligent are pre-service teachers? Teaching and Teacher Education, 28(5), 750-759.

Corcoran, R. P., \& Tormey, R. (2012b). Assessing emotional intelligence and its impact in caring professions: The value of a mixed-methods approach in emotional intelligence work with teachers. In A. Di Fabio (Ed.), Emotional intelligence: New perspectives and applications (pp. 215-238). Croatia: InTech.

Corcoran, R. P., \& Tormey, R. (2013). Does emotional intelligence predict student teachers' performance? Teaching and Teacher Education, 35, 34-42.

Cozolino, L. (2013). The social neuroscience of education: Optimizing attachment and learning in the classroom. New York, NY: W. W. Norton \& Company.

Crystal, D. (2003). English as a global language. Cambridge: Cambridge University Press.

Day, C., \& Gu, Q. (2009). Teacher emotions: Well being and effectiveness. In P. A. Schutz\& M. Zembylas (Eds.), Advances in teacher emotion research: The impact on teachers' lives (pp. 15-32). Dordrecht: Springer.

Day, C., \& Gu, Q. (2010). The new lives of teachers. Abingdon: Routledge.

Decety, J., \& Cacioppo, J. T. (Eds.). (2015). The Oxford handbook of social neuroscience. New York, NY: Oxford University Press.

Denham, S. A., Bassett, H. H., \& Wyatt, T. M. (2010). Gender differences in the socialization of preschoolers' emotional competence. New Directions for Child and Adolescent Development, 2010(128), 29-49.

Denham, S. A., \& Brown, C. (2010). "Plays nice with others": Social-emotional learning and academic success. Early Education and Development, 21(5), 652-680.

Dewaele, J.-M. (2010). Emotions in multiple languages. Basingstoke: Palgrave Macmillan. 
Dewaele, J.-M., Petrides, K. V., \& Furnham, A. (2008). The effects of trait emotional intelligence and sociobiographical variables on communicative anxiety and foreign language anxiety among adult multilinguals: A review and empirical investigation. Language Learning, 58(4), 911-960.

Dörnyei, Z., \& Murphey, T. (2003). Group dynamics in the language classroom. Cambridge: Cambridge University Press.

Durlak, J. A., Weissberg, R. P., Dymnicki, A. B., Taylor, R. D., \& Schellinger, K. B. (2011). The impact of enhancing students' social and emotional learning: A meta-analysis of school-based universal interventions. Child Development, 82(1), 405-432.

Elias, M. J., \& Arnold, H. (Eds.). (2006). The educator's guide to emotional intelligence and academic achievement: Social-emotional learning in the classroom. Thousand Oaks, CA: Corwin.

Fernández-Berrocal, P., Salovey, P., Vera, A., Extremera, N., \& Ramos, N. (2005). Cultural influences on the relation between perceived emotional intelligence and depression. International Review of Social Psychology, 18(1), 91-107.

Frenzel, A. C., \& Stephens, E. J. (2013). Emotions. In. N. C. Hall \& T. Goetz (Ed.), Emotion, motivation, and self-regulation: A handbook for teachers (pp. 1-56). Bingley, UK: Emerald.

Furrer, C. J., Skinner, E. A., \& Pitzer, J. R. (2014). The influence of teacher and peer relationships on students' classroom engagement and everyday motivational resilience. National Society for the Study of Education, 113(1), 101-123.

Gardner, H. (1983). Frames of mind. New York: Basic Book Inc.

Garner, P. W., Robertson, S., \& Smith, G. (1997). Preschool children's emotional expressions with peers: The roles of gender and emotion socialization. Sex Roles, 36, 675-691. 
Garside, R. B., \& Klimes-Dougan, B. (2002). Socialization of discrete negative emotions: Gender differences and links with psychological distress. Sex Roles, 47, 115-128.

Ghorbani, N., Bing, M. N., Watson, P. J., Kristl Davison, H., \& Mack, D. A. (2002). Selfreported emotional intelligence: Construct similarity and functional dissimilarity of higher-order processing in Iran and the United States. International Journal of Psychology, 37(5), 297-308.

Goleman, D. (1995). Emotional intelligence: Why it can matter more than IQ. New York: Bantam Books.

Goleman, D. (1998). Working with emotional intelligence. New York: Bantam Books.

Goleman, D. (2006). Social intelligence: The new science of human relationships. London: Arrow Books.

Golombek, P. R., \& Doran, M. (2014). Unifying cognition, emotion, and activity in language teacher professional development. Teaching and Teacher Education, 39, 102-111.

Golombek, P. R., \& Johnson, K. E. (2004). Narrative inquiry as a mediational space: Examining emotional and cognitive dissonance in second-language teachers' development. Teachers and Teaching: Theory and Practice, 10(3), 307-327.

Gregersen, T., MacIntyre, P. D., Finegan, K. H., Talbot, K., \& Claman, S. (2014). Examining emotional intelligence within the context of positive psychology interventions. Studies in Second Language Learning and Teaching, 4(2), 327-353.

Hargreaves, A. (2000). Mixed emotions: Teachers' perceptions of their interactions with students. Teaching and Teacher Education, 16(8), 811-826.

Hatch, T., \& Kornhaber, M. L. (2006). Multiple intelligences and emotional intelligence: Finding common ground in the classroom. In M. J. Elias \& H. Arnold (Eds.), The educator's guide to emotional intelligence and academic achievement (pp. 35-42). Thousand Oaks, CA: Corwin Press. 
Hattie, J. (2009). Visible learning: A synthesis of over 800 meta-analyses relating to achievement. Abingdon: Routledge.

Humphrey, N. (2013). Social and emotional learning: A critical appraisal. London: Sage.

Imai, Y. (2010). Emotions in SLA: New insights from collaborative learning for an EFL classroom. The Modern Language Journal, 94(2), 278-292.

Jennings, P. A., \& Greenberg, M. T. (2009). The prosocial classroom: Teacher social and emotional competence in relation to student and classroom outcomes. Review of Educational Research, 79(1), 491-525.

King, J. (2015). "It's time, put on the smile, it's time!": The emotional labour of second language teaching within a Japanese university. In C. Gkonou, D. Tatzl \& S. Mercer (Eds.), New directions in language learning psychology (pp. 97-112). Berlin: Springer.

Lieberman, M. D. (2013). Social: Why our brains are wired to connect. Oxford: Oxford University Press.

MacIntyre, P. D., Gregersen, T., \& Mercer, S. (Eds.). (2016). Positive psychology in second language acquisition. Bristol: Multilingual Matters.

Mayer, J. D., Salovey, P., \& Caruso, D. R. (2008). Emotional intelligence: New ability or eclectic mix of traits? American Psychologist, 63, 503-517.

Mercer, S. (2016). Seeing the world through your eyes: Empathy in language learning and teaching. In P. D. MacIntyre, T. Gregersen, \& S. Mercer (Eds.), Positive psychology in second language acquisition. Bristol: Multilingual Matters.

Merrell, K. W., \& Gueldner, B. A. (2010). Social and emotional learning in the classroom: Promoting mental health and academic success. New York: The Guildford Press. 
Meyer, D. K., \& Turner, J. C. (2007). Scaffolding emotions in classrooms. In P. A. Schutz \& R. Pekrun (Eds.), Emotion in education (pp. 243-258). Burlington, MA: Academic Press.

Moafian, F., \& Ghanizadeh, A. (2009). The relationship between Iranian EFL teachers' emotional intelligence and their self-efficacy in Language Institutes. System, 37(4), 708718.

Morris, E., \& Casey, J. (2006). Developing emotionally literate staff: A practical guide. Thousand Oaks, CA: Sage.

Nelis, D., Quoidbach, J., Mikolajczak, M., \& Hansenne, M. (2009). Increasing emotional intelligence: (How) is it possible? Personality and Individual Differences, 47(1), 36-41.

Nizielski, S., Hallum, S., Lopes, P. N., \& Schütz, A. (2012). Attention to student needs mediates the relationship between teacher emotional intelligence and student misconduct in the classroom. Journal of Psychoeducational Assessment, 30(4), 320-329.

Oz, H., Demirezen, M., \& Pourfeiz, J. (2015). Emotional intelligence and attitudes towards foreign language learning: Pursuit of relevance and implications. Procedia-Social and Behavioral Sciences, 186, 416-423.

Petrides, K. V., \& Furnham, A. (2006). The role of trait emotional intelligence in a genderspecific model of organizational variables. Journal of Applied Social Psychology, 36, $552-569$.

Petrides, K. V., Furnham, A., \& Martin, G. N. (2004). Estimates of emotional and psychometric intelligence: Evidence for gender-based stereotypes. The Journal of Social Psychology, 144(2), 149-162.

Powell, W., \& Kusuma-Powell, O. (2010). Becoming an emotionally intelligent teacher. Thousand Oaks, CA: Corwin.

Rasoal, C., Eklund, J., \& Hansen, E. M. (2011). Toward a conceptualization of ethnocultural empathy. Journal of Social, Evolutionary, and Cultural Psychology, 5(1), 1-13. 
Reissman, R. (2006). Raising your new teacher's emotional intelligence: How using socialemotional competences can make your first year of teaching less stressful and more successful. In M. J. Elias \& H. Arnold (Eds.), The educator's guide to emotional intelligence and academic achievement (pp. 76-82). Thousand Oaks, CA: Corwin Press.

Salovey, P., \& Mayer, D. (1990). Emotional intelligence. Imagination, Cognition and Personality, 9(3), 185-211.

Shao, K., Yu, W., \& Ji, Z. (2013). An exploration of Chinese EFL students' emotional intelligence and foreign language anxiety. The Modern Language Journal, 97(4), 917929.

Shipper, F., Kincaid, J., Rotondo, D. M., \& Hoffman, R. C. (2003). A cross-cultural exploratory study of the linkage between emotional intelligence and managerial effectiveness. International Journal of Organizational Analysis, 11(3), 171-191.

Spencer-Oatey, H., \& Franklin, P. (2014). Intercultural interaction: A multidisciplinary approach to intercultural communication. Basingstoke: Palgrave Macmillan.

Spendlove, D. (2008). Emotional literacy. London: Continuum.

Tassinari, M. G. (2015). Emotions and feelings in language advising discourse. In C.

Gkonou, D. Tatzl \& S. Mercer (Eds.), New directions in language learning psychology (pp. 71-96). Berlin: Springer.

Thorndike, E. L. (1920). Intelligence and its uses. Harper's Magazine, 140, 227-235.

Tsang, K. K. (2011). Emotional labor of teaching. Educational Research, 2(8), 1312-1316.

Underhill, A. (2013). The Inner Workbench: Learning itself as a meaningful activity. In J. Arnold \& T. Murphey (Eds.), Meaningful action: Earl Stevick's influence on language teaching (pp. 202-218). Cambridge: Cambridge University Press. 
Weare, K. (2004). Developing the emotionally literate school. London: Paul Chapman.

Weinstein, C. S. (1999). Reflections on best practices and promising programs. In H. J. Freiberg (Ed.), Beyond behaviorism: Changing the classroom management paradigm (pp. 145-163). Boston: Allyn \& Bacon.

Williams, M., Mercer, S., \& Ryan, S. (2015). Exploring psychology in language learning and teaching. Oxford: Oxford University Press.

Zeidner, M., Matthews, G., \& Roberts, R. D. (2001). Slow down, you move too fast: Emotional intelligence remains an "elusive" intelligence. Emotion, 1(3), 265-275.

Zembylas, M. (2005). Teaching with emotion: A postmodern enactment. Greenwich, CT: Information Age Publishing.

Zembylas, M. (2007). Emotional ecology: The intersection of emotional knowledge and pedagogical content knowledge in teaching. Teaching and Teacher Education, 23(4), 355367.

Zins, J. E., \& Elias, M. J. (2006). Social and emotional learning. In G. G. Bear \& K. M. Minke (Eds.), Children's needs III: Development, prevention, and intervention (pp. 1-13). Bethesda, MD: NASP Publications.

Zins, J. E., Weissberg, R. P., Wang, M. C., \& Walberg, H. J. (Eds.). (2004). Building academic success onsocial and emotional learning: What does the research say? New York: Teachers College Press. 